\section{Image of a Local Area: Measuring and Managing}

Vincenzo Vignieri

Department of Political Sciences and

International relations, University of Palermo, Palermo, Italy

\section{Synonyms}

Image of local area; Impression of a place; Place conceptualization; Place perception; Representation of a territory

\section{Definition}

The image of a local area can be conceived as cumulative beliefs, ideas, opinions, and experiences people have about a place. Image embodies a large number of information, memories, and suggestions that pertain to a specific place, which are processed by human mind by selecting relevant evidence from a big amount of data about a local area. Image conceptualizes the value and/ or a certain level of performance that a place expresses and it inspires human behaviors. The image of a local area is perceiveid by people, it is part of knowledge structures related to a place and it is long-lasting and difficult to change. Measuring and managing the image of a local area can support the socioeconomic development of a local community by providing to local policy-makers the necessary information to support them in improving policy outcomes. When applied to a local area, an outcome-based dynamic performance management approach provides decisionmakers with the appropriate set of information to effectively allocate resources coherently with the pursued objectives. In this task, performance drivers provide to both managers and politicians relevant measures which give insights and policy recommendation on how to manage the image of local area.

\section{Introduction}

The image of a country image has become a crucial success factor, and governments are called to manage their country reputation, especially when domestic firms look to expand their markets overseas. The image of a country is not under the marketer's control - unlike product or corporate brand - but it has a big impact. "In fact, there remains much misunderstanding and many commentators and some consultants and academics still interpret 'place branding' as simply the application of product promotion, public relations, and corporate identity activities for countries, cities, or regions, as though they are mere commodities" (Porter 2011: 1).

Places, like brands, have an image that "represents a promise of value and performance, incite beliefs, evoke emotion and inspire behaviors" 
(Kotler and Gertner 2011: 35). If the marketing department of a business organization may leverage products and brand image with investments, for local policy-makers managing the image of a place is not an easy task. As Kotler and Gertner (2011: 35) emphasized, the image of a place can be conceived as "the sum of beliefs and impressions people have about places. Image represents a simplification of a large number of associations and pieces of information connected with a place. They are a product of the mind, trying to process and pick out essential information from huge amounts of data about a place." Place image represents knowledge structures related to places, which are long-lasting and difficult to change (Kotler and Gertner 2011: 35). Place image is "the total of all descriptive, inferential and informational beliefs one has about a particular country (Porter 1995). Images represent a simplification of a large number of associations and pieces of information connected with a place (Porter 2011: 1).

At local level policy-makers have to act alike, if they want to attract business ventures and tourists or to export local products. To manage the image of a local area local policy-makers have to face a number of challenges. They are called to frame the sources of that image, understand what the driving factors are, and lastly, identify some leverage points which act for designing sustainable public policies. This context demands for an outcome-based performance management system which allows decision-makers to measure both the "output" - or the volume of products and services completed or delivered - and the "outcome," the results, the effects, or the consequences of service delivery that are important to the public.

Studies on place-image relationships are mainly focused at national scale and take a marketing perspective, and only a few authors have investigated the country image from a managerial and institutional perspective. In addition, as Matarazzo (2012: 38) pointed out, main weakness in the literature on country-image relationships is related to the fact that a majority of studies in the field, have employed quantitative techniques to measure a limited set of categories causing a lack of exploratory research.
The purpose of this work is threefold: it aims to explain the sources of the image of a local area, offer both a framework and associated measures to manage it. To this end, this research suggests to adopt an interinstitutional outcome-based Dynamic Performance Management (DPM) approach to measure and manage the driving factors of the image of a tourism destination.

\section{Discussing the Relationships between Place and Image}

Two important constructs characterize the studies on the relationships between place and image: this literature distinguishes them as the "Country of Origin Effects" (CoO) and the "Competitive Identity."

The "Country of Origin Effects" is adopted to explain the influence, either positive or negative, that the country of origin of a product has on consumer behavior. Literature on $\mathrm{CoO}$ classifies such a concept in two formulations: halo and summary effects (Han 1989). The halo effect is the influence made by the country of origin on consumers' purchase intention when there is a lack of experience with a given product and thus potential customers evaluate products using their perceived country image that rely on the general knowledge they have about the country itself, including its people, and its level of economic, political, and social development. Through country image, consumers may develop an attitude toward a brand. Therefore, their purchase intentions mature (Han 1989, 1990). The halo effect has the following relationship:

\section{Country image $\rightarrow$ Beliefs $\rightarrow$ Brand attitude}

Summary effect takes place when consumers are unfamiliar with a product from a particular country, but they have experiences with other products from the same country. Hence, consumers may use their experiences, as well as mass media information or word-of-mouth, to develop an attitude toward that product (Johansson 1989). Han clarified that when it comes to the summary construct, consumers 
derive a country image from products information about product attributes.

$$
\begin{aligned}
\text { Beliefs about product } & \rightarrow \text { Country image } \\
& \rightarrow \text { Brand attitude }
\end{aligned}
$$

The two effects are highly connected. Fruchter, Jaffe, and Nebenzahl (2006) presented a dynamic model that includes both halo and summary constructs. Without product familiarity, the country image affects the purchase decisions. After purchases, consumers mature experiences with products that allow them to adjust the country image according to the recent experience. The more the country image relies on the most recent experiences with products, the more it works as summary. "The direct effect of country image reflects its use as a summary construct, while the indirect effect, through product beliefs, represents consumers' use of country image as a halo" (Matarazzo 2012: 32).

A second construct which has contributed to the literature on place-image relationships is the competitive identity theory developed by Simon Anholt (2007). At the core of this framework, there is the idea that "country's (and, by extension, cities and regions too) reputation is associated with domestic identity, politics, and economics rather with branding as it is for businesses in the commercial sector" (Anholt 2011: 21).

Although places do have brand images, they are not primarily about marketing, as it has often been assumed. Place image is a perception and it does not reside in the municipality or tourist agencies' offices. It exists in the mind of the people; it is stored in a remote location, hence talking about the image of a place means to manage the attributes of this location and then the story told through media about this location (Kotler et al. 1978).

According to Anholt's perspective, the most valuable asset for a country is the name of the country itself, which evokes its image. Governments, local administrations, and entrepreneurs only to mention a few - are called to manage the world's perception of their place image and to develop a strategy for managing it.

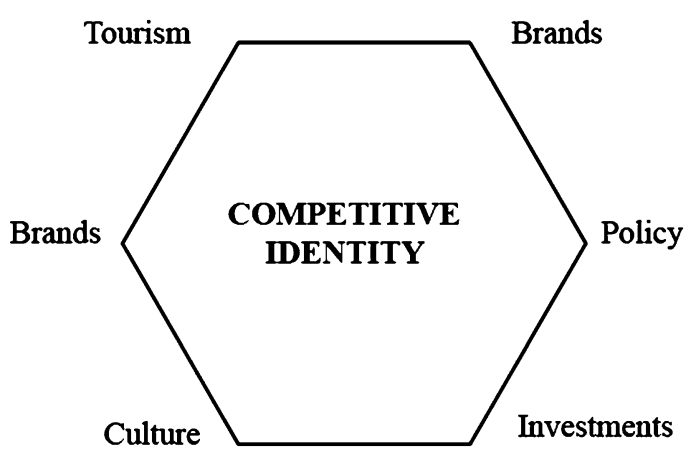

Image of a Local Area: Measuring and Managing, Fig. 1 The hexagon of Competitive Identity (Anholt 2007: 26)

Anholt developed a model (Fig. 1) which incorporated six areas of activities that a country should address to build a strong place image. Particularly, places have to undertake tourism promotion activities and improving experiences in visiting the place, since both function as wordof-mouth mechanisms in influencing the image of place. The products exported from a place are the ambassadors of that place and they communicate its value and tradition. The political decisions making as it is reflected by mass media. The method is used by a place to attract investments like businesses, human resources, or foreign companies. A place should support cultural exchange and activities aimed at hosting international events and exporting local heritage through the museums, bands, and theaters. Lastly, the way residents behave abroad and how they treat tourists and visitors at their home country.

The basic theory behind the hexagon is: for decision-makers to build a positive image, they have to develop a clear idea of what a place is and stands for and then they have to manage and coordinate all the six points of the hexagon.

What Anholt's approach emphasizes is that place image can be neither built nor changed through communication: it is not a marketing concern and communication may help only in spreading what a country makes and does. To build and manage a strong competitive identity, local decision-makers need to develop a strategy (goals), to create real substance (implementation 
actions) and do not overlook just symbolic actions (communication) (Anholt 2011: 28).

The concept of $\mathrm{CoO}$ communicates the effects the image of a place has on consumer behavior as well as the implication for firms that want to exploit its effect. What $\mathrm{CoO}$ studies are not able to explain is how a place can build such an image.

Even though the "Competitive Identity" hexagon tries to create a systemic way of looking at the image of an area, the research used statistical techniques that are suitable for cross-national comparative analysis through indexes, but they are not able to explain the underlying causes of place's image dynamics.

The image of a local area does not rely only on what various public institutions do, but it is a multifaceted, synthetic result of the overall geographic area including different institutions, public and private organizations, citizens, and firms too.

A local area is characterized by a dynamic environment where public organizations are loosely coupled (Meyer 2002): i.e., municipalities, as well as regional administration, are in charge of promoting tourism in the area, but they operate without any strategic alignment. There is a weak coordination in the interplay between public and private actors' strategies that lead to high degree of fragmentation of development policies. There are significant delays between policy adoption and related effect because the latter quite often depends on the availability of funds from the European Union and the investments lag behind formal decisions (Bianchi 2010a). To frame the sources of a local area image, it is necessary to broaden and enhance the standpoint, embracing an interinstitutional outcome-based perspective.

\section{A Dynamic Approach to Frame the Sources of the Local Area Image}

"Places compete in attracting visitors, residents, and businesses [...] a place with a positive reputation finds it easier to vie for attention, resources, people, jobs and money; a positive place reputation builds place competitiveness" (Morgan et al. 2012: 3). If a local area wants to develop sustainably it needs to manage its image actively and both public and private organizations need to discover what the perception of their place is, and to develop a strategy for managing it. Thus, local actors are called to attract investments, public funds, infrastructures, companies, population, human capital, tourism, arts, and global events. This implies consideration of a systemic approach according to which the performance of a local area lies behind the capability of both sectors to generate value individually (Bianchi 2010b). If one adopts such a point of view, this development challenge requires coordination and an outcome perspective when assessing the impact of policies on local area performance and long-term sustainability.

To make decision-makers aware of the possible behavior of a set of crucial system variable, it is necessary to blend span and depth of performance measurement/management tools. In other words, such a change requires to integrate inputs, activities, outputs, and effects/outcomes with strategic and operational objectives and associated measures, at the organizational level (micro), at the policy level (meso), and the interinstitutional level (macro) (Bianchi 2010b). The objectives derive from an environment whose structure influences the outcomes for the local area, and in turn its generation is essential for the overall system's development as well as to raise sufficient resources (Borgonovi 2002) to maintain it. At the interinstitutional level, the interaction among policies of different institutions strongly influences performance. The advantages to adopt an interinstitutional perspective is to capture the outcomes, as achieved by the broader context of the local area. Such a point of view could be defined as external, meaning that a "formal model can be considered to be objective instances of a reality domain" (Größler 2010: 385) since it does not reflect the observation point of a specific decision-maker. SD models aim at producing "qualitative statements about modes of behavior, appropriate performance indicators and effective leverage points" (Lane 2012: 591). Insight SD modeling is an established practice used to inform the understanding of processes (Ghaffarzadegan et al. 2011). DPM by combining SD methodology with performance management systems enriches 
the perception of the investigated problematic behavior. DPM through conceptual models identifies the structure behind problems and enhances the understanding of the causal connection of a given time development.

As Bianchi (2012: 149) pointed out "conventional financially focused $\mathrm{P} \& \mathrm{C}$ systems have been considered lacking in relevance since they are not able to provide information that can support either dynamic complexity management, the measurement of intangibles, the detection of delays and to deal with the sustainable growth." A sustainable growth is characterized by a condition according to which the rate of change of the endowment of strategic resources is in balance with underlying resources utilization processes. By taking this perspective, accumulation and depletion processes of shared strategic resources strongly influence the local area's performance, therefore to manage a local area's performance, it is crucial to define key success factors driving such a performance. Fig. 2 shows the relationship between strategic resources, performance drivers, and end-results of both outputs and outcomes.

As Fig. 2 portrays, DPM requires that end results be explicit. Consequently, it is necessary to identify performance measures which are able to capture both end-results and associated performance drivers. Drivers are ratios (i.e., as a ratio between an organization or a local area's performance and a benchmark, or target) and they represent those factors able to explain, cause, and fuel the end results. While the numerator of a performance driver is the current state of performance, the denominator can be a benchmark/target/ desired value, against which compares the actual result. As Fig. 2 shows, decision-makers have to act on the upstream level changing the linked strategic resources. If decision makers act alike, they may affect performance drivers and, in turn, improve end-results. It is through the end-results that they can build up, preserve, and deploy strategic resources. Managing strategic resources to affect both performance drivers and end-results in accordance with the other system's players is a complex task, especially because intangible resources (i.e., image, reputation, social capital) are difficult to define as well as to measure, but they play a significant role in affecting performance. Such a task is complex due to inherent delays that make difficult to perceive the effects generated by decisions. Delays, together with nonlinear relationships, are major cause of tradeoffs in time and space, to understand and counteract such phenomena DPM offers an effective method.

\section{Modeling Local Area Image through an Outcome-Based Dynamic Performance Management View}

As Forrester (1992: 56) emphasized, the information for understating the causalities behind phenomena can be attained from different sources: from decision-makers' "mental database" to numerical databases. Likewise, as Yin (2013: 116) put it, "no single source has a complete advantage," therefore many sources should be used. Therefore, to develop the model multiple sources of evidence have been used: interviews with local decision-makers and semi-structured interviews with local entrepreneurs have been performed; district documents, statistical databases have been read; comments and feedbacks on tourism- and travel-oriented websites have been coded (Fig. 3).

Box 1 Case Study: "Taormina Etna District" "Taormina Etna district" is the brand for a local development agency that supports firms and municipalities located between Messina and Catania, along the Sicilian East Coast. Since the beginning of the 1990s, Integrated Territorial Projects (ITPs are a modality of implementation of European structural funds. ITPs were introduced for "objective 1" programs and were then extended to the other types of regions. ITPs are a combination of different measures deriving from the structural funds on the basis of local strategies designed by local partnerships. The selection of projects

(continued) 


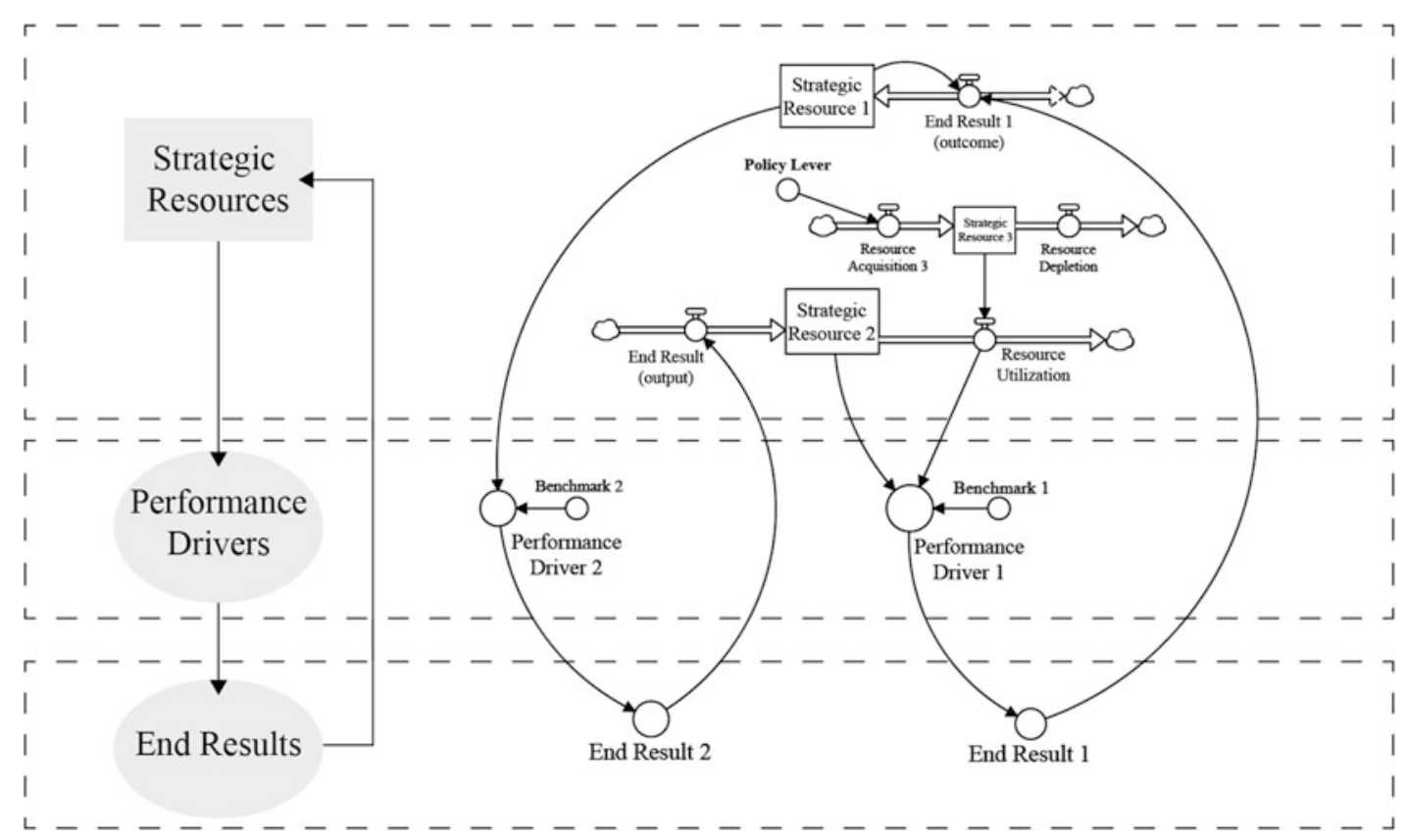

Image of a Local Area: Measuring and Managing, Fig. 2 The dynamic perspective of performance (Adapted from Bianchi 2016: 73)

\section{Box 1 Case Study: "Taormina Etna District"} (continued)

is usually made by regions on the basis of criteria agreed upon with local partnerships.) (ITPs) defined Italian local development policies. These projects have become a powerful instrument to foster local sustainable development and a vehicle to involve the lowest levels of the Italian governmental in the long-term strategies. In Sicily, many municipalities have created agencies as a form of public-private partnerships aiming at (i) coordinating growth strategies, (ii) monitoring investments and secure funding from different sources, (iii) supporting projects development to capitalize on local resources and tackle those factors limiting the socioeconomic growth.

In its territory, the district includes two famous icons of Sicily: the city of Taormina and the Etna volcano. The area characterized by a coastline includes three natural

\section{Box 1 Case Study: "Taormina Etna District"} (continued)

parks and four natural preserves; it is full of small villages rich in history, local cultures, products, and popular traditions. Taormina has been an international icon of tourism since the end of World War II. It has been a destination for luxury tourism, intellectuals, and VIPs such as writers and royalty.

Another icon of the area is the Etna volcano that lies above the convergent plate margin between the African Plate and the Eurasian Plate. It is the tallest active volcano in Europe currently $3329 \mathrm{~m}$ (10,922 ft.) high. In June 2013, UNESCO added ETNA to the list of World Heritage Sites. It represents a noteworthy attraction for tourists and a great resource for the local economy. The fertile volcanic soils support extensive agriculture, with vineyards and orchards spread across the lower slopes of 


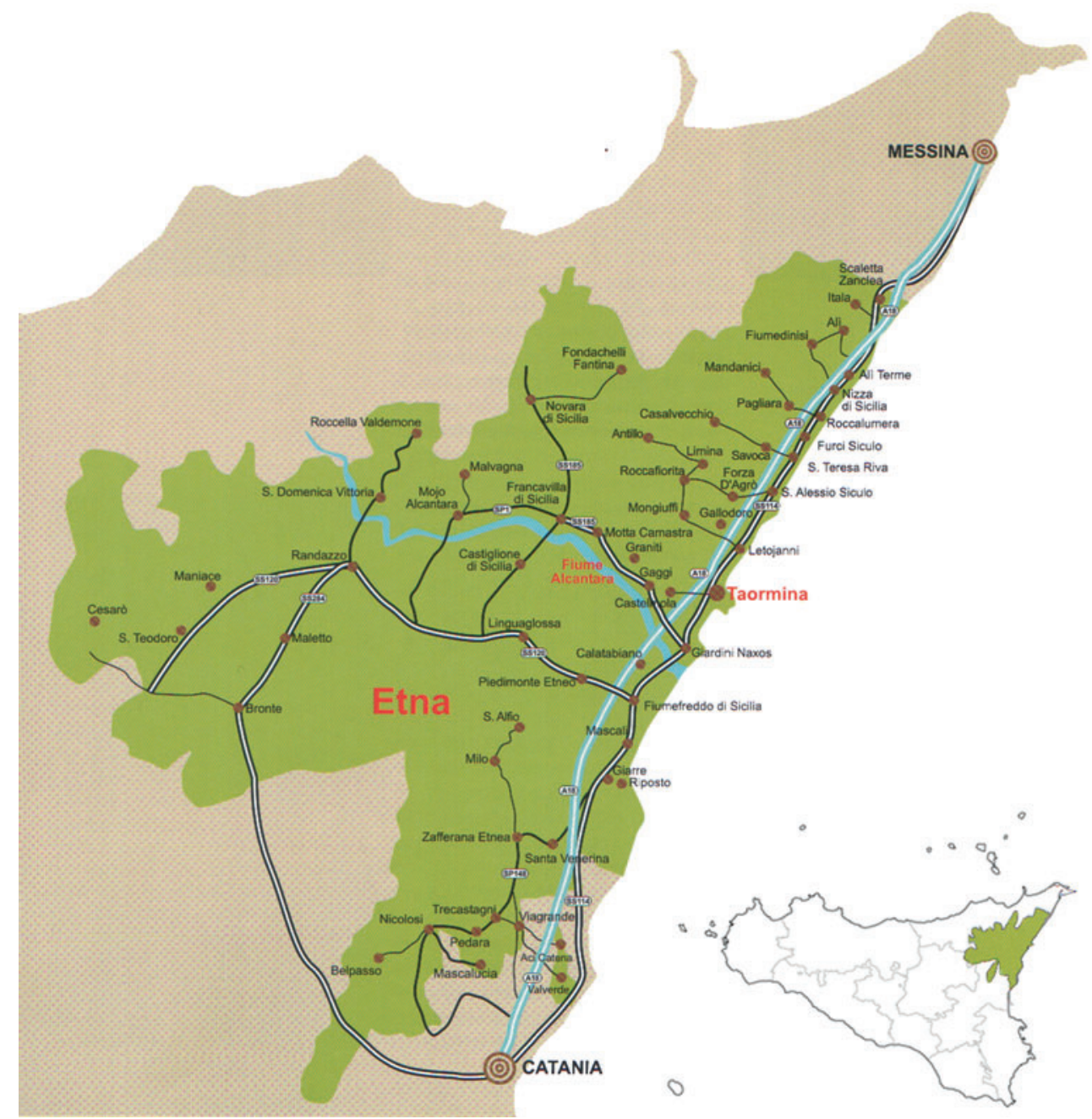

Image of a Local Area: Measuring and Managing, Fig. 3 The geographical area of "Taormina-Etna district"

Box 1 Case Study: "Taormina Etna District" (continued)

the mountain and the broad Plain of Catania to the south.

The aim of the district is to well manage local, natural, and cultural resources through the enhancement of hospitality infrastructures, the implementation and promotion of local products and traditions as well as the education of human resources (DTE 2009: 3). To achieve such goals
Box 1 Case Study: "Taormina Etna District" (continued)

"Taormina-Etna district" has operated through project-based activities aimed at attracting funds from national, regional, and European programs. The district received funds for five ITPs through which it spent more than EUR150 million (59\% as public funds, $41 \%$ as private capital). The funds have been used to subsidize businesses, create public infrastructures, and 


\section{Box 1 Case Study: "Taormina Etna District"} (continued)

support touristic marketing initiatives (DTE 2015).

The realization of the ITPs has created new business ventures and has provided opportunities for local entrepreneurs to increase the operations of their firms. The promotional initiatives have generated a certain amount of contacts between the district and the potential market. All of these results are at best output of strategies or indicate just an input acquisition since they represent a prerequisite to produce value for the local community.

The model portrayed in Fig. 4 is the result of interviews, conference reports, and archival records. It shows causal relationships and evidences four synthetic factors influencing the image of the local area.

Defining the four constructs of the causal model portrayed in Fig. 4:

- Level of tourism development denotes the position of the destination in a specific phase of the evolution cycle. It reflects the growth rate of tourism in the area by considering arrivals, presence, and the average length of the holiday. Such a measure influences the strategies of local organizations as the destination goes through its cycle. The more tourists in the area, the higher the willingness of people to invest in the local area will be. Those investments may change the local area image.

- Fit of contextual attributes depends on the local promotion, cultural and environmental policies. It synthesizes the use of the land, natural attractions, cultural attractions, artificial facilities, and easiness to visit the attractions around the places in which the tourists reside. It captures how the tourists live in and experience with the local area.

- Strength of identity stands for the promotion of typical local products, local heritage, and local traditions towards the tourists. It also includes the degree of integration between the producers, if they use local raw materials in producing their products or if they share innovation project. Strength of identity tries to illustrate the extent by which the place talks about its history and values through museums, products, and food.

- Synergy between public and private sector means that public and private organizations run projects aimed at improving their own respective results, such as networking activity among hotels, restaurants, and museums; websites and info-points to share information about the destination; a unique label to certify the local production.

The factors from one to three are additive, while the synergy between public and private works as multiplier of the first three elements. Table 1 links the first-level performance drivers with second-level, connecting associated measures.

\section{Sketching a Dynamic Performance Management Chart to Manage the Local Area Image}

The model is composed of two fundamental equations, where the image is modeled as adaptive expectation through the exponential smoothing of its source. In this way, the model - as the simplest information stock does - adjusts the belief to the actual value of the input variable (The input value is the sum of three first-level performance drivers, multiplied by the synergy between public and private sector.) gradually. The change in the image of the local area (1) updates the perceived value of the local area image (2), according to a certain perception time.

$$
\begin{aligned}
& \text { Change in local area image } \\
& =\frac{(((\mathrm{TD}+\mathrm{CA}+\mathrm{I}) * S Y N)-\text { Local area Image })}{\text { Time to change image }}
\end{aligned}
$$




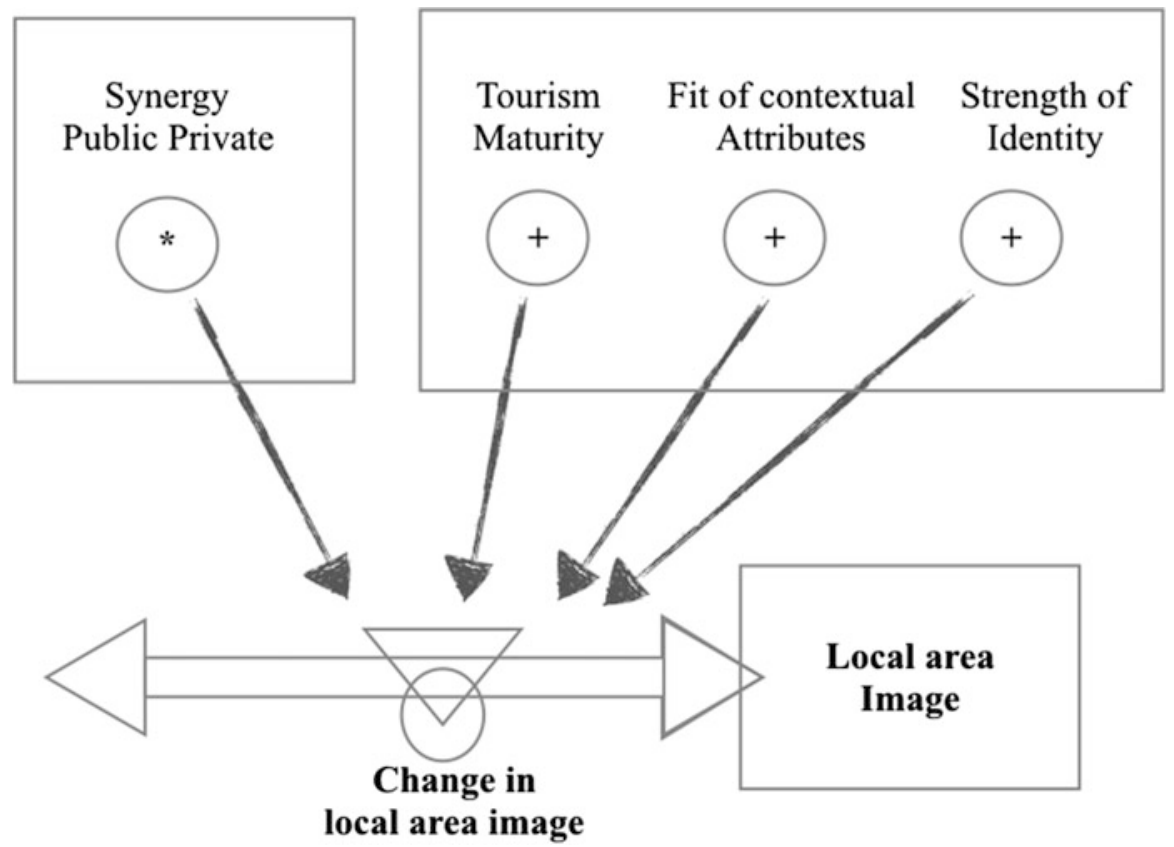

Image of a Local Area: Measuring and Managing, Fig. 4 The sources of the local area image (simplified version of the SD model)

$$
\begin{aligned}
& \text { Local area image } \\
& =\int_{0}^{t} \text { Change in local area image } * D T \\
& + \text { Local area image }_{t 0}
\end{aligned}
$$

As equation (These abbreviations can be found in Table 1.) 1 shows, the four first-level performance drivers affect the "change in local area image." The four first-level performance drivers are the multiplication of the relative normalized second-level performance drivers. Indeed, they compare a current state of the system with a given benchmark (i.e., a target value, a competitor value, or a desired level). The following equations present the first-level performance drivers as composed by the second-level performance drivers (In an SD model, those drivers normalized through a benchmark value. This value works for a nondimensional input to the table lookup function that converts this input into a min-max scalable output.). Equations 3, 4, 5, and 6 represent the first-level performance drivers as part of an SD model.
Level of Tourism development $(T D)$

$$
\begin{aligned}
= & \left(\frac{T G R}{\text { Target } T G R}\right) *\left(\frac{B G R}{\text { Sicilian } B G R}\right) \\
& *\left(\frac{W A H L}{\text { Target } W A H L}\right)
\end{aligned}
$$

Fit of contextual attributes $(C A)$

$$
\begin{aligned}
= & \left(\frac{A V G S Z}{\text { Desired } A V G S Z}\right) *\left(\frac{\text { Sicilian } U D}{U D}\right) \\
& *\left(\frac{A S}{\text { Target } A D}\right)
\end{aligned}
$$

Strenght of local identity (I)

$$
\begin{aligned}
= & \left(\frac{L A R}{\text { Target } L A R}\right) *\left(\frac{T Y P}{\text { Desired TYP }}\right) \\
& *\left(\frac{I S C}{\text { Desired ISC }}\right)
\end{aligned}
$$


Image of a Local Area: Measuring and Managing, Table 1 Performance drivers (bold, abbreviation in parenthesis), definition (italic), and measure

\begin{tabular}{|c|c|c|}
\hline First-level performance drivers & Second-level performance drivers & Measures \\
\hline \multirow{3}{*}{$\begin{array}{l}\text { Level of tourism development } \\
\text { (TD) }\end{array}$} & Tourist fractional growth rate (TGR) & $\%$ \\
\hline & Bed fractional growth rate (BGR) & $\%$ \\
\hline & Weighted average holiday length (WAHL) & Days \\
\hline \multirow{3}{*}{$\begin{array}{l}\text { Fit of contextual attributes } \\
\text { (CA) }\end{array}$} & Average structure's size (AVG-ST-SIZE) & Bed/structure \\
\hline & $\begin{array}{l}\text { Urban density (UD) } \\
\text { Urbanized land/total land }\end{array}$ & Dimensionless \\
\hline & $\begin{array}{l}\text { Attraction density (AD) } \\
\text { Total attraction/local area surface }\end{array}$ & Attractions $/ \mathrm{m}^{2}$ \\
\hline \multirow[t]{3}{*}{ Strength of identity (I) } & $\begin{array}{l}\text { Local-oriented attraction ratio (LAR) } \\
\text { Number of local-oriented attraction/total attraction }\end{array}$ & Dimensionless \\
\hline & $\begin{array}{l}\text { Typical labeled product ratio (TYP) } \\
\text { Number of firms producing labeled products/total firms }\end{array}$ & Dimensionless \\
\hline & $\begin{array}{l}\text { Integration of supply chain (ISC) } \\
\text { Number of restaurants using local products/total restaurants }\end{array}$ & Dimensionless \\
\hline \multirow[t]{3}{*}{$\begin{array}{l}\text { Synergy between public and } \\
\text { private sector (SYN) }\end{array}$} & $\begin{array}{l}\text { Integration of innovation, i.e., internationalization, R\&D, know } \\
\text { how (INN) } \\
\text { Number of firms sharing a project/total firms }\end{array}$ & Dimensionless \\
\hline & $\begin{array}{l}\text { Density and scope of touristic circuit (DSTC) } \\
\text { Number of affiliated activities* category of activities*(surface of } \\
\text { covered municipality/total land surface) }\end{array}$ & Dimensionless \\
\hline & $\begin{array}{l}\text { Strategic dialogue in the local area (STDLG) } \\
\text { Number. Of agreement achieved/total agreement }\end{array}$ & Dimensionless \\
\hline
\end{tabular}

After having defined the performance drivers, the next section of the work will discuss how DPM may support decisionmakers in managing the image of a local area and to improve the local area's performance sustainably

Synergy between public and private $(S Y N)$

$$
\begin{aligned}
= & \left(\frac{I N N}{\text { Desired INN }}\right) *\left(\frac{D S T C}{\text { Desired DSTC }}\right) \\
& *\left(\frac{S T D L G}{\text { Target } S T D L G}\right)
\end{aligned}
$$

Once the performance drivers are pointed out, the linked strategic resources are made explicit. Thus, the leverage points upon which the decision-makers can intervene to affect the outcome - through the performance drivers - are clearly revealed. In this way, each decision-maker may identify those strategic resources he manages and understand which output he should improve.

As Fig. 5 shows, the change in the local area image will increase the perceived local area image, which in turn, - all other things being equal - will cause an increase in tourism arrivals; an increasing number of tourists means more value for the local area to support the policies.

The end result is affected by four first-level performance drivers, which comprise 12 secondlevel performance drivers that in turn depend on the strategic resources. As the DPM chart (Fig. 5) clearly shows, it is not possible to affect performance drivers directly since they compare a current state of performance with a given benchmark. It is, rather, possible to design policies to affect the upstream strategic resources in order to influence the drivers, and finally to improve the outcome.

The driver "fit of contextual attributes" synthesizes the suitability of contextual attributes with tourism activities. To increase such drivers, it is necessary to increase the strategic resources "attraction" (i.e., by renovation of heritage building, by opening museums). On the other side an increase in the number of building (i.e., houses for holidays, apartment building for citizens) also increases urban density and it will reduce the "fit 


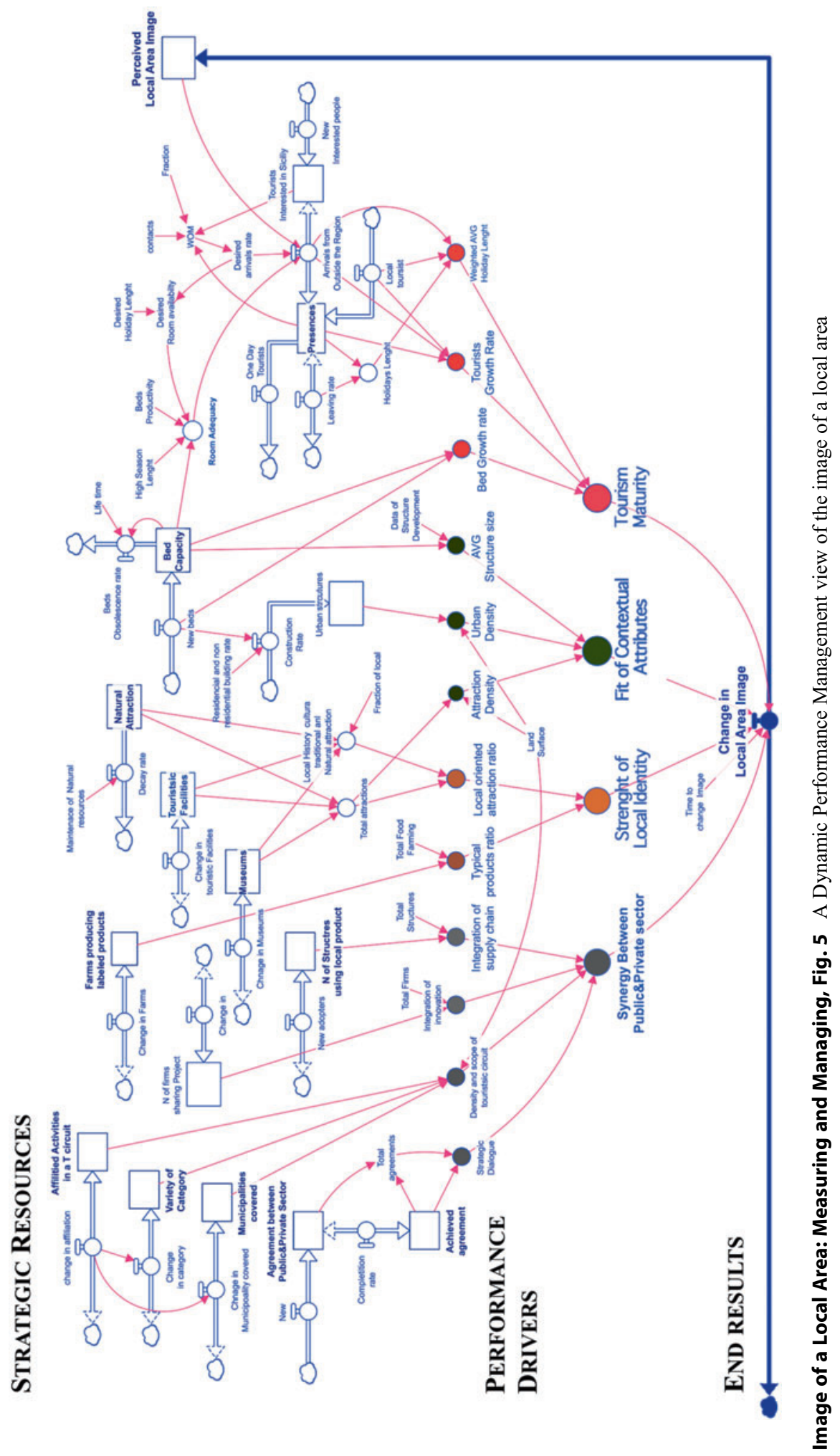


of contextual attributes." Policy makers may strengthen local identity by increasing the strategic resource "attractions" that relates to local history and cultures, likewise the number of firms producing typical products. The performance driver "Level of Tourism development" captures the lifecycle of the destination by considering the growth rate of tourists, the weighted average of the holiday length, and the bed growth rate. These measures gives suggestions about the need of new/better clear destination positioning.

The most effective way to improve image is through synergy between the public and private sectors. It compounds the policy-makers' results in the other three driving factors. If the number of attractions is increased but that is not linked with accommodation services and transportation facilities or not listed on tourism websites, the image can only be slightly improved. In the same fashion, the firms producing typical products should supply local restaurants, jointly run projects (i.e., $\mathrm{R} \& \mathrm{D}$, internationalization, export consortia), and together with public institutions outline strategic plans for the local area. Increasing the synergy between both private and public sector will spread out the positive effect throughout the system.

By following the discussion of the model, it is possible to give some policy suggestions to decision-makers. They may want to consider a more balanced approach to image management, which could include all or most of those performance drivers described in this research. They should manage the size of the hospitality structure, avoiding both super small structures that raise the per-night prices and super big hotels that increase soil erosion and concentrate tourists in one place. Local history and tradition should be more connected with natural attractions (beaches and mountains) and leisure, and typical products should be standard ingredients in local restaurants. Policy-makers should network the small municipalities and the private sectors in a more comprehensive tourist package, increasing the scope of the journey across the local area. Before moving to the conclusions, it is important to make clear the limitations of the model. According to
Sterman (2002: 513), "the most important assumptions of a model are not in the equations, but what's not in them; not in the documentation, but unstated; not in the variables on the computer screen, but in the blank spaces around them." The model here discussed is necessarily limited regarding the number of feedback loops described, because a large number of factors should be included and taken into account to map all the relevant feedbacks. Weaknesses involve some of the linkages between each organization and the entire system. For that reason, the DPM analysis presented here considers only the main feedback loop involving the performance drivers affecting the end-result under investigation.

\section{Conclusions}

To frame the image of a local area this work has proposed an outcome-based DPM perspective, which differentiates this work from established studies on place-image relationships. The DPM chart connects institutional outputs with the interinstitutional outcome. However, the model discussed in this work needs to be further developed into a simulation model. Such an advancement may help policy-makers in understanding the dynamics of accumulation and depletion processes of strategic resources and in assessing the sustainability of alternative policies. Through dynamic simulation, one may show how performance drivers interact, influence each other, behave over time, and identify the effectiveness of alternative leverage points. The model identifies four main driving factors (i.e., four performance drivers): the level of tourism development, the fit of contextual attributes, the strength of identity, and the synergy between public and private sector. These performance drivers - in combination with twelve indicators (i.e., second level performance drivers) - enable decision-makers to adopt performance measures which give insights and policy recommendation on how to measure and manage the image of local area. 


\section{Cross-References}

\author{
- Local Governance \\ > Performance Management
}

\section{References}

Anholt S (2007) Competitive identity. Palgrave Macmillan UK, Basingstoke

Anholt S (2011) Beyond the nation brand:the role of image and identity in international relations. Exchange 2(1):1-7

Bianchi C (2010a) Improving performance and fostering accountability in the public sector through system dynamics modelling: from an 'external'to an 'internal'perspective. Syst Res Behav Sci 27(4): 361-384

Bianchi C (2010b) Improving performance and fostering accountability in the public sector through system dynamics modelling: from an 'external' to an 'internal' perspective. Syst Res Behav Sci 27(4):361-384

Bianchi C (2012) Enhancing performance management and sustainable organizational growth through system-dynamics modelling. In: Grösser SN, Zeier R (eds) Systemic Management for Intelligent Organizations. Springer, Berlin, pp 143-161

Borgonovi E (2002) Principi e sistemi aziendali per le amministrazioni pubbliche. EGEA, Milano

DTE (2009) Distretto Taormina Etna: Luglio 2001 - Aprile 2009. Catania

DTE (2015) The Museum of the Etna's historical identity. Catania

Forrester JW (1992) Policies, decisions and information sources for modeling. Eur J Oper Res 59(1):42-63

Fruchter GE, Jaffe ED, Nebenzahl ID (2006) Dynamic brand-image-based production location decisions. Automatica 42(8):1371-1380

Ghaffarzadegan N, Lyneis J, Richardson GP (2011) How small system dynamics models can help the public policy process. Syst Dyn Rev 27(1):22-44
Größler A (2010) Policies, politics and polity: comment on the paper by Bianchi. Syst Res Behav Sci 27(4):385-389

Han CM (1989) Country image: halo or summary construct? J Mark Res 26(2):222

Han CM (1990) Testing the role of country image in consumer choice behaviour. Eur J Mark 24(6):24-40

Johansson JK (1989) Determinants and effects of the use of "Made in" labels. Int Mark Rev 6(1):47-58

Kotler P, Ravazzi G, Salinas G (1978) Al servizio del pubblico. Etas, Milano

Kotler P, Gertner D (2011) A place marketing and place branding perspective revisited. In: Morgan $\mathrm{N}$, Pritchard A, Pride R (eds) Destination brands: managing place reputation. Butterworth-Heinemann, Oxford, UK, pp 33-53

Lane DC (2012) What is a 'policy insight'? Syst Res Behav Sci 29(6):590-595

Matarazzo M (2012) Country of origin effect: research evolution, basic constructs and firm implications. In: Bertoli G, Resciniti R (eds) International marketing and the country of origin effect: the global impact of 'made in Italy'. Edward Elgar, Cheltenham, UK, pp 23-42

Meyer H-D (2002) From "loose coupling" to "tight management"? Making sense of the changing landscape in management and organization theory. J Educ Adm 40(6):515-520

Morgan N, Pritchard A, Pride R (2012) Destination brands. Managing place reputation. Taylor \& Francis, Oxford, UK

Porter ME (1995) The competitive advantage of the inner city. Harv Bus Rev 73(3):55-71

Porter ME (2011) Competitive advantage of nations: creating and sustaining superior performance. Free Press, New York

Sterman J (2002) All models are wrong: reflections on becoming a systems scientist. Syst Dyn Rev 18(4):501-531

Yin RK (2013) Case study research: design and methods. SAGE, Thousand Oaks 